\title{
El paisaje agrario de Castellón de la Plana
}

\author{
Javier Saura Gargallo \\ Universidad de Valencia \\ javi_s_g@hotmail.es
}

\begin{abstract}
Resumen. El espacio agrario de Castellón de la Plana es predominantemente un paisaje de regadío. La huerta castellonense ocupaba a finales del siglo XV las tres quintas partes del espacio total cultivado. El regadío castellonense se estructuraba sobre un sistema hidráulico plenamente consolidado en los siglos bajomedievales, al menos en sus elementos fundamentales. El espacio agrario se componía de una serie de elementos que, junto con la red de irrigación, conformaban un paisaje humanizado con una personalidad propia. La red viaria, la difusión de molinos, alquerías, mases y otras instalaciones agrarias, el parcelario o la tipología de los cultivos eran los elementos que caracterizaban el paisaje rural castellonense. A pesar de que la estructura agraria castellonense presentaba las características básicas que definían la actividad agraria en el territorio valenciano, el impacto de la crisis bajomedieval provocaría una serie de transformaciones de gran calado en el paisaje agrario castellonense. El espacio cultivado se redujo en las últimas décadas del siglo $\mathrm{XV}$, aunque la contracción se produjo a costa de las tierras menos productivas. La actividad agraria se concentró en las tierras más fértiles del regadío. Las transformaciones afectaron también a la distribución de los cultivos y a las formas de organización de las explotaciones, produciéndose una verdadera reconversión agraria.
\end{abstract}

Palabras clave: Paisaje. Regadío. Estructura agraria. Castellón de la Plana. Siglo XV.

\begin{abstract}
The agrarian landscape of Castellón de la Plana is predominantly an irrigated countryside. The buerta of Castellon occupied three-fifths of the total cropped area at the end of the $15^{\text {th }}$ century. The Castellón's irrigation was a structured hydraulic system which was fully consolidated at the late medieval centuries, almost in its fundamental elements. The agrarian landscape was formed by a group of elements that, with also the irrigation network, maked an humanized landscape with its own personality. The road network, the diffusion of mills, alquerias, mases, and other agricultural installations, the parcel and the type of cultures were the elements that characterized the Castellón's rural landscape. Although the agrarian structure of Castellon had the basic defining characteristics which defined the agricultural activity in the Valencia region, the impact of late medieval crises lead to a series of major transformations in the Castellón's agrarian landscape. The cultivated area was reduced in the last decades of the fifteenth century, although the contraction occurred at the expense of the less productive land. The agricultural activity was concentrated in the most fertile irrigated lands. The changes affected the distribution of cultures and the ways of organization of farms, causing a real agrarian reorganization.
\end{abstract}

Keywords: Landscape. Irrigation. Agrarian Structure. Castellón de la Plana. 15 $5^{\text {th }}$ Century.

\section{Introducción}

El regadío es uno de los paisajes rurales más característicos del territorio valenciano. Muchas de las huertas valencianas tienen siglos de historia, configurando un paisaje cultural que, en ciertos lugares y siempre con transformaciones, ha perdurado hasta nuestros días. Es el caso de Castellón de la Plana, cuya huerta histórica se encontraba ya plenamente configurada desde la Edad Media. El espacio irrigado castellonense se mantendría desde el período medieval casi inalterado, al menos en su estructura básica, hasta las transformaciones de época contemporánea.

Para reconstruir la estructura agraria castellonense a finales del siglo XV contamos con una excepcional fuente histórica, el Libro de la Peita de $1497^{1}$. Los libros de la peita de

\footnotetext{
${ }^{1}$ Archivo Histórico Municipal de Castellón, Libro de Values de la Peita, 1497.
} 
Castellón de la Plana son una serie de documentos de carácter fiscal que presentan las características propias de los padrones de riqueza ${ }^{2}$. El estudio de esta fuente documental ha permitido realizar una reconstrucción del paisaje y de la estructura agraria castellonense en el tránsito entre la Edad Media y la Moderna. Un paisaje fuertemente humanizado, transformado a raíz de la crisis económica bajomedieval, y en el cual el regadío era el elemento más importante.

\section{Contexto}

La estructura agraria medieval de los territorios valencianos presentaba una serie de características básicas bien definidas. Se trataba de una agricultura fundamentalmente de regadío, con espacios de secano en las zonas interiores. El cereal era el principal cultivo, junto con la viña, el olivo y otros cultivos característicos del ámbito mediterráneo. Predominaba la pequeña explotación agrícola, compuesta por una serie de parcelas, frecuentemente dispersas y separadas entre sí. El parcelario se caracterizaba por la atomización y fragmentación de los campos. Una estructura parcelaria condicionada por los factores ecológicos y técnicos, pero a la vez adaptada a la estructura social y económica del territorio.

En los siglos XIV y XV, el Reino de Valencia vivió el impacto de la crisis bajomedieval. La crisis provocó una serie de transformaciones de gran relieve en el campo valenciano, que estimularon una mejor integración de la agricultura en el conjunto de la economía y favorecieron la modernización de la estructura agraria. Entre las principales novedades encontramos la introducción de nuevos cultivos (arroz, morera, caña de azúcar), el desarrollo de formas innovadoras de gestión de las explotaciones, la difusión de nuevas formas contractuales de tenencia de la tierra, o la creciente importancia del crédito y el endeudamiento en la economía campesina. El mercado pasó a ser un elemento fundamental en el mundo rural valenciano.

La villa de Castellón de la Plana se encuadraba dentro de este contexto particular. Castellón fue, durante los siglos bajomedievales, uno de los principales centros urbanos del norte del Reino de Valencia. Era villa de realengo desde 1368 y sede de la gobernación dellà lo Uixò (Sánchez Adell, 1982, p. 34). Junta a las funciones administrativas, en Castellón se desarrollaría una actividad comercial de cierta importancia, así como una producción artesanal orientada al abastecimiento de la demanda local. Entre las actividades económicas de la villa en la Edad Media tenía, sin embargo, una importancia clave la agricultura. El peso de la actividad agraria se plasmaba en la estructura socioprofesional castellonense. En 1497, de un total de 496 contribuyentes cristianos y de género masculino, un 68,2\% eran labradores, un $18,1 \%$ artesanos, un $8,2 \%$ burgueses y profesionales, un 3,6 \% clérigos y un 1,6\% pequeños nobles (Viciano, 2008a, pp. 66-71).

\footnotetext{
${ }^{2}$ Entre los principales trabajos dedicados al estudio de los padrones de riqueza valencianos en la Edad Media, destacar los de Furió (1982), Peris Albentosa (1985) y Viciano (2008b). Para los Libros de Values de la Peita de Castellón de la Plana, destacar Sánchez Adell (1973), Doménech Vallés y Joli Bonias (1996-1997), y Domingo (1998).
} 


\section{El espacio agrario}

Castellón se asienta sobre una fértil llanura sedimentaria que recibe el nombre de la Plana. Su término municipal actual comprende 10.750 ha de superficie. Los límites municipales contemporáneos se corresponden, a grandes rasgos, con los mismos que tenía la villa en época medieval exceptuando el antiguo término de Fadrell, que era propiedad de la orden de Santiago. Durante el período medieval, el espacio cultivado ocupó una extensión reducida, entre un 20 y un $30 \%$ del total del término. En la Tabla 1 se puede consultar la superficie total cultivada a lo largo del siglo $\mathrm{XV}^{3}$.

Tabla 1. Superficie total cultivada

\begin{tabular}{lll}
\hline Año & Superficie (hanegadas) & $\begin{array}{l}\text { Superficie } \\
\text { (hectáreas) }\end{array}$ \\
\hline 1398 & 26.733 & 2.222 \\
1468 & 36.672 & 3.048 \\
1497 & 31.642 & 2.630 \\
\hline
\end{tabular}

Se observa cómo la extensión de los cultivos se incrementó a lo largo de los tres primeros tercios del siglo XV. Sin embargo, en las décadas finales de la centuria se produjo un retroceso del espacio roturado, que se redujo en 1497 a un 86\% del existente en 1468. Entre las principales causas de dicha reducción podemos destacar el descenso demográfico que afectó a la villa a finales del XV. Si en 1469 el número de hogares en Castellón era de 626, en 1499 se había reducido a 484 (Guinot, 1988, p. 242). La falta de brazos para trabajar la tierra y el presumible descenso de la demanda interna de productos agrarios favorecieron la contracción del espacio cultivado. Sin embargo, los factores demográficos no son los únicos que pueden explicar dicho proceso, ya que entre 1398 y 1468 se produjo una lenta pero constante disminución de la población en Castellón (de 972 fuegos en 1415 se pasó a 626 en 1469), hecho que no impidió un extraordinario incremento de las tierras cultivadas. En todo caso, sí se puede decir que el "hambre de tierras" que había caracterizado las primeras décadas del siglo se había frenado a finales de la centuria. No se puede interpretar, sin embargo, este retroceso en clave negativa. Otros indicadores se mostraban favorables, como la proporción de tierra cultivada por vecino. Si en 1398 la superfície media de tierra por contribuyente era de 3,5 ha, en 1468 era de 4,35 ha y en 1497 se había incrementado hasta las 4,6 ha (Sánchez Adell, 1973: 45; Domingo, 1977: 55) ${ }^{4}$. Más que en clave de crisis productiva, debemos interpretar este fenómeno en términos de reconversión agraria, como sucederá con el resto de transformaciones que analizaremos en los apartados siguientes.

\footnotetext{
${ }^{3}$ Los datos relativos a 1398 y 1468 proceden, respectivamente, de Sánchez Adell (1973) y Domingo (1977). Los datos aportados respecto a 1497 son fruto de la investigación del autor del presente estudio. La superficie hace referencia, tanto en esta tabla como en el resto del trabajo, a la suma del valor superficial de las parcelas en las que se detalla su extensión en los libros de la peita. Sin embargo, este valor superficial se puede considerar como un valor mínimo siempre, ya que en la fuente documental existen un número variable de parcelas de las que no se detalla su superficie y que, por tanto, no han computado dentro de los cálculos de la extensión superficial cultivada. Para la conversión a hectáreas de la medida agraria que utiliza la fuente, la fanecada de Castellón, se ha utilizado la equivalencia 1 hanegada=0,083108 ha (Domingo, 1981-1982: 13).

${ }^{4}$ Los datos relativos a 1497 se han obtenido dividiendo la superficie cultivada entre el número total de contribuyentes.
} 


\subsection{El regadío y el secano}

Los dos grandes espacios dentro del paisaje agrario castellonense han sido, tradicionalmente, el regadío y el secano. Los datos con los que contábamos para 1398 y 1468 , fruto de los primeros estudios realizados, mostraban una superficie irrigada muy reducida, en torno a las 227-228 ha (Sánchez Adell, 1973: 38; Domingo, 1983, p. 25). Dichos cálculos eran resultado tanto de las insuficiencias que caracterizaban a las fuentes documentales utilizadas, como del empleo de un criterio excesivamente conservador a la hora de contabilizar las parcelas de regadío. A la luz de estos datos, Domingo, estableció la hipótesis de que, a lo largo de la Edad Media, la superficie ocupada por la huerta había sido muy reducida. La expansión del regadío y la consolidación definitiva de la red hidráulica no llegarían hasta el siglo XVI, ofreciendo la imagen de una agricultura castellonense atrasada y poco desarrollada para el período medieval (Domingo, 1983, pp. 29-30).

Utilizando nuevas fuentes documentales y reinterpretando los datos anteriores, Rabassa (1999) establecería una nueva teoría acerca de la extensión del regadío medieval castellonense. Según este autor, el sistema hidráulico que abastecía la huerta castellonense se encontraba ya consolidado a principios del siglo XIV. En este momento el diseño de la huerta castellonense se encontraría ya finalizado en sus elementos estructurales básicos. Dicho autor elevaba la superficie del regadío medieval de Castellón por encima de las 2.000 ha, definiendo un paisaje agrario dominado claramente por el regadío. La tesis de Rabassa se convertiría en la interpretación de referencia ${ }^{5}$.

La información proporcionada por el Libro de la Peita de 1497, que resumimos en la Tabla 2, permite validar la hipótesis de Rabassa. El predominio del regadío sobre el secano se muestra tanto en término cuantitativos, por la mayor extensión del regadío; como cualitativos, dada la mayor capacidad productiva de las tierras irrigadas. La cifra excesivamente optimista de 2.000 ha para la superficie total de la huerta queda, sin embargo, reducida a una extensión más modesta.

Tabla 2. Superficie cultivada en 1497

\begin{tabular}{llll}
\hline Tipo de suelo & Superficie (hanegadas) & $\begin{array}{l}\text { Superficie } \\
\text { (hectáreas) }\end{array}$ & $\begin{array}{l}\text { Porcentaje } \\
\text { respecto al total }\end{array}$ \\
\hline Regadío & 18.791 & 1.562 & $59,4 \%$ \\
Secano & 11.944 & 993 & $36,5 \%$ \\
Indeterminado & 907 & 75 & $2,8 \%$ \\
\hline
\end{tabular}

${ }^{5}$ La validez de esta interpretación sería aceptada también por Domingo (2005: 51-52). 
Según estos datos, la extensión del regadío en Castellón de la Plana ocupaba casi el 60 \% del total cultivado. Las tierras de secano tenían un papel secundario en el espacio agrario castellonense, aunque no por ello menos importante. Para valorar estos datos en una perspectiva más amplia, indicar que en 1599 la superficie total cultivada era de 5.728 ha, de las cuales 1.655 ha serían de regadío (Domingo, 1983, pp. 33-36). La comparativa muestra cómo ya en la Baja Edad Media la huerta castellonense había llegado casi a su extensión óptima.

El retroceso de la tierra cultivada que hemos detectado en las últimas décadas del siglo XV se produciría principalmente a costa de las tierras marginales. Los productores castellonenses reaccionarían ante las dificultades concentrando la actividad agraria en las zonas más productivas de regadío. Las parcelas más alejadas, de menor calidad y menos productivas de secano y de marjal se abandonarían. Las tierras de regadío, que eran las más cercanas al núcleo de población y las más productivas, no se verían tan afectadas por dicha reducción del total roturado. Estableciendo una superficie aproximada de tierra huerta de 1.600 ha para 1468 , podemos hablar de un retroceso de casi 400 ha de tierra de secano en tres décadas. Las tierras de marjal también se redujeron notablemente. De las 128 ha de marjal a finales del siglo XIV y 299 ha en 1468, se pasó en 1497 a únicamente 45 ha ${ }^{6}$.

\subsection{E1 sistema hidráulico}

El trazado de la red hidráulica medieval se puede localizar todavía en el actual paisaje agrario castellonense. La huerta histórica de Castellón era regada por medio de las aguas del río Millars, dada la ausencia de puntos de captación hídrica de importancia dentro del término municipal. La organización de la red de acequias era, en Castellón de la Plana, el elemento que determinaba qué tierras eran susceptibles de recibir agua de riego. Las tierras ubicadas por encima de la línea de rigidez trazada por la acequia Mayor no podrían ser regadas más que con el agua de lluvia y con las escasas aportaciones de balsas y pozos aislados.

En el término de Castellón convivían dos sistemas hidráulicos, ambos abastecidos por el Millars ${ }^{7}$. Uno se organizaba en torno a la acequia de Almalafa, abasteciendo la parte sudeste del término y la encomienda de Fadrell, territorio jurisdiccionalmente independiente del municipio de Castellón. El segundo, que regaba la mayor parte del término, era el que estructuraba la acequia Mayor. Una vez superaba hacia el norte el entramado urbano de Castellón, la acequia Mayor se dividía en dos ramales. El principal, que mantenía el nombre de acequia Mayor, recibía el $61 \%$ del caudal hídrico. El segundo, que recogiendo el $29 \%$ del caudal hídrico discurría como acequia somera, pasaba a denominarse acequia de Coscollosa (Guinot, 2002, p. 96).

El Libro de la Peita de 1497 recoge gran parte de la hidronimia de la huerta castellonense. La relación, de sur a norte, de las acequias y filas que nacían de la acequia Mayor es la siguiente: Sequiol, acequia Mitjana (que nacía del molino de Alçamora), fila d'en Dalmau, fila del Moro, fila dels Dos Ulls, fila d'en Pinós; acequia de Rafalafena, fila de la Safra, fila de Taxida, fila de la Plana, fila de Ramell, filas d'en Ocelló, acequia del molino del Romeral y acequia Travessera.

\footnotetext{
${ }^{6}$ En la Tabla 2, las tierras de marjal han sido consideradas como tierras de regadío. En el cómputo se han contabilizado también las tierrasde exutal, un tipo particular de marjal.

${ }^{7}$ Para más información acerca de la red hidráulica de Castellón de la Plana a lo largo de su historia, consultar Guinot (2002).
} 
Exceptuando el Sequiol y la acequia Mitjana, todas nacían en el margen oriental de la acequia Mayor y circulaban en dirección este, hacia el mar, perpendiculares a la acequia madre. De la acequia de Almalafa partían las acequias de Vinamargo y del Pont d'en Valero. Comparando el listado de acequias localizadas con el que aporta V. Traver para 1588, podemos observar que las principales acequias ya existían desde época medieval (Traver, 1982, pp. 139-146).

La huerta se ubicaba en una franja paralela a la costa, que tenía como límite por el oeste y el norte la acequia Mayor-Coscollosa. Entre la huerta y el mar Mediterráneo se extendían las marjales, zonas bajas inundadas en principio poco aptas para la actividad humana. La zona de transición entre la marjalería y las tierras de cultivo, el límite oeste del regadío, era delimitado por el camino de la Donació. La marjal fue poco a poco conquistada por medio de una ardua labor de bonificación, que permitió poner en cultivo tierras anteriormente estériles. El sistema hidráulico se prolongaba en la marjal, convirtiéndose este espacio en la continuación natural de la huerta. Las acequias de riego, al penetrar en la marjal, se convertían en acequias de desagüe denominadas escorredors, que canalizaban el agua sobrante y drenaban las tierras inundadas (Torró, 2010, p. 168).

La infraestructura hidráulica era un elemento fundamental para la agricultura de Castellón. El agua de riego era el elemento que permitía incrementar exponencialmente los rendimientos de las tierras de cultivo. Las parcelas de huerta situadas en la zona oeste, las más cercanas a la acequia madre, serían las que recibirían un caudal más regular y abundante y por tanto las más productivas. Eran también las más cercanas a las murallas de la villa, las que fueron roturadas en fechas más tempranas y las mejor valoradas a efectos fiscales. Las tierras de regadío situadas en los niveles inferiores, principalmente las ubicadas por debajo del Caminás, recibirían un aporte hídrico menos cuantioso y más irregular, al igual que las parcelas situadas en la zona norte de la huerta ${ }^{8}$.

La ubicación de una parcela dentro del espacio irrigado tenía, por tanto, una importancia enorme. Un cierto número de propiedades se localizaban junto a acequias y canales de riego. Se han localizado 196 de un total de 2.262 parcelas de tierra huerta ubicadas junto a una acequia o canal de riego, con una superfície conjunta de 141 ha de superfície (un $9 \%$ de la extensión del regadío), cosa que muestra una densidad relativa de la red hídrica.

\subsection{La red viaria}

Los caminos y vías de comunicación configuraban, junto con el sistema hidráulico, las líneas de fuerza del paisaje agrario. La red de caminos medieval de Castellón también se ha preservado en parte hasta la actualidad, a pesar del crecimiento urbanístico e industrial. La red viaria se encontraba formada por vías y caminos de diversa entidad. En el secano era la red viaria el elemento que ordenaba y estructuraba el espacio. Los ejes de comunicación en el secano eran el camino Real, los caminos que unían Castellón con los núcleos vecinos (caminos de Almassora, de Vila-real, de Borriol, de Benicássim), así como los caminos del Collet, del Coll de la Garrofera, del Castell Vell. Estos caminos tejían una red viaria de morfología radial en el oeste del término con epicentro en el núcleo urbano. Junto a estas vías, una serie de caminos transversales o cuadras cruzaban el secano en dirección surnorte, paralelos al camino real. Los caminos actuarían frecuentemente como frentes de roturación, siendo las tierras colindantes a las vías las que primero se ponían en cultivo.

\footnotetext{
8 Para más información sobre las tandas de riego de la acequia Mayor de Castellón, ver Rabassa (1999) y Guinot (2002).
} 
La red viaria era considerablemente más densa en el regadío. En la huerta presentaba una morfología ortogonal, en la cual los caminos paralelos al mar (el Caminás, la Donacio) eran atravesados por una multitud de caminos perpendiculares, entre los cuales destacaba el camino del Mar. En un nivel inferior, una serie de caminos menores y sendas se encargaban de comunicar estas vías principales con los molinos, las casas de campo, las instalaciones agropecuarias y los campos de cultivo. Un total de 719 parcelas en el regadío y 215 en el secano (un 23,9\% del total de parcelas) se ubicaban en las inmediaciones de un camino.

\subsection{Edificios y construcciones rurales}

El paisaje rural valenciano se compone de un gran número de elementos, más allá del medio natural, de las tierras de cultivo, de los caminos que las comunican y de las acequias que las riegan. Un variado conjunto de edificios e instalaciones, construidos para dar apoyo a la actividad agropecuaria, salpicaban el espacio rural de Castellón dando un carácter distintivo al territorio.

\section{Molinos}

Los molinos eran las principales instalaciones agrarias de la cultura mediterránea. Artefactos imprescindibles para la transformación del grano en harinas panificables, estaban también presentes en el paisaje de Castellón. En 1497 se han localizado 14 molinos hidráulicos, de los cuales hasta 10 podrían haber sido molinos harineros, mientras que 4 eran molinos aceiteros. Dada la ausencia de cursos hídricos de importancia dentro del término de Castellón, todos los molinos se localizaban sobre acequias de riego. La fuente documental identifica claramente como harineros cinco molinos: el molino Primer, el Mitjá, el Jussá o Darrer (los tres ubicados en la acequia Mayor una vez ésta ha superado el partidor de Coscollosa), el de Almalafa y el Soterrani (cada uno sobre la acequia del mismo nombre). Otros han sido identificados como molinos harineros en otros trabajos, como el molino Roder o el del Romeral, ambos sobre la acequia Mayor (Guinot, 2002, p. 101). El molí de la Font fue utilizado varios años también como batán, aunque no sabemos bien si en 1497 era éste su uso. Sí tenemos constancia que el molino de Alçamora, el molino más valioso según el libro de la peita, había sido convertido recientemente en molino pañero ${ }^{9}$. No sabemos si también siguió moliendo grano o se limitó exclusivamente a la actividad textil después de la reforma. El molino del camino del Mar, llamado en el Libro de la Peita de 1497 el Molinás, se encontraba seguramente fuera de uso dado su exiguo valor fiscal. La presencia de cuatro molinos de aceite confirmaba el creciente peso que estaba adquiriendo el olivo dentro del paisaje agrario castellonense, proceso que analizaremos en el apartado dedicado a los cultivos.

\footnotetext{
${ }^{9}$ En 1494 su propietario, el paraire Joan Santalínea, obtenía el permiso para realizar las reformas necesarias para convertirlo en batán. Ver: Navarro Espinach (1998, p. 163).
} 


\section{Alquerías y mases}

Las alquerías y los mases, en el contexto del espacio rural valenciano bajomedieval, se pueden definir como construcciones de carácter disperso, ubicadas dentro del espacio rural y dedicadas a la actividad agropecuaria. La principal diferencia entre ambos se encuentra en su ubicación: las alquerías son características del regadío, los mases del secano. En Castellón las primeras tuvieron una mayor importancia dentro de la actividad productiva, y no sólo por su mayor número. Las alquerías de la Plana castellonense se caracterizaban por ser edificios vinculados a explotaciones agrarias, en ocasiones con diversas instalaciones agrarias anexas, de arquitectura sencilla y alejadas del modelo de gran alquería señorial que se podía localizar en la Huerta de Valencia (Guinot, 2008, p. 107; Aparici Martí, 2009, p. 109). La evolución del número de casas de campo se puede consultar en la Tabla $4{ }^{10}$.

Tabla 4. Evolución del número de alquerías y mases

\begin{tabular}{ccccccc}
\hline Año & 1398 & 1468 & 1479 & 1497 & 1588 & 1599 \\
\hline Número de alquerias & 8 & 8 & 45 & 60 & 130 & 152 \\
Número de mases & 3 & 1 & 5 & 6 & 5 & 9 \\
Total & 11 & 9 & 51 & 66 & 135 & 161 \\
\hline
\end{tabular}

El número de casas de campo se incrementó de forma espectacular en las últimas décadas del siglo XV y continuó en la centuria siguiente. Destaca especialmente el período 14681479, en el cual se quintuplica su número. A finales del siglo XV ya eran un elemento destacado del paisaje productivo, consolidándose su importancia en los siglos posteriores. Para establecer una comparación, indicar que el número de alquerias de la Huerta periurbana de Valencia, a finales del siglo XV, se situaba entre 50 y 80 según los fogajes fiscales, aunque probablemente su número real superaba las 150 (Viciano, 2011).

Es difícil valorar el papel real que jugarían las alquerías y los mases en el espacio rural castellonense. La hipótesis más plausible parece indicar que estas construcciones formarían parte de una estrategia de racionalización de la gestión de las explotaciones agrarias. La mayor parte de estas casas rurales contaban con una serie de tierras anexas de extensión variable. En el caso de las alquerías castellonenses, se han identificado procesos de concentración parcelaria organizados en torno a estas construcciones, que contrastan con la estructura de la propiedad predominante, caracterizada por la fragmentación y dispersión de las parcelas dentro de una misma explotación. Los propietarios utilizararían estas construcciones como mecanismo para crear explotaciones agrarias agrupadas, con el objetivo de facilitar el trabajo agrícola.

\section{Instalaciones agropecuarias}

Junto a los molinos y casas de campo, propiedad de individuos particulares y enriquecidos, encontramos un gran número de instalaciones agrarias, representadas en la Tabla 5. Eran menos espectaculares y caras, pero más numerosas y también imprescindibles para el trabajo agrícola y ganadero. Estas construcciones se podían localizar intramuros, en las inmediaciones del núcleo urbano, o dispersas en el espacio rural.

10 Datos obtenidos de Sánchez Adell (1973: 42), Domingo (1983, pp. 237-240) y Traver Tomás (1982, pp. 143-156); y de los libros de la peita de 1479 y 1497, del Archivo Histórico Municipal de Castellón de la Plana. 
Tabla 5. Instalaciones agropecuarias auxiliares

\begin{tabular}{ccc}
\hline Tipo de instalación & Número total & Ubicadas en el espacio rural \\
\hline Corral & 115 & 7 \\
Era & 42 & 6 \\
Bodega & 10 & - \\
Pajar & 2 & - \\
Noria & 2 & 2 \\
Pozo & 1 & 1 \\
Palomar & 1 & 1 \\
Algar & 1 & 1 \\
\hline
\end{tabular}

\subsection{Partidas y topónimos}

La delimitación de partidas dentro de un término era un mecanismo tanto de ordenación del espacio como de humanización del territorio. En Castellón, la mayor parte de topónimos rurales tienen un orígen medieval. A pesar de que la mayoría de las actuales partidas del término castellonense ya existían a finales del siglo XV, el concepto de partida en la Edad Media era más elástico que el actual. Los límites de las partidas medievales no siempre parecían claros, usándose en ocasiones el concepto de forma vaga y vacilante. Se ha podido realizar una aproximación a la superficie de las principales partidas, resumida en la Tabla 6. El gran número de parcelas en las que no consta su localización provoca que estos datos sean todavía limitados, ya que seguramente la extensión real de cada una de las partidas sería mucho mayor. La fuente documental recoge asimismo un gran número de topónimos, no recopilados en este artículo, que hablan de la riqueza del paisaje castellonense (Domingo, 1986; Sánchez Adell, 1994).

Tabla 6. Superficie de las partidas

\begin{tabular}{cccccc}
\hline $\begin{array}{c}\text { Partidas de } \\
\text { regadío }\end{array}$ & $\begin{array}{c}\text { Superficie } \\
\text { (hectáreas) }\end{array}$ & Partidas de secano & $\begin{array}{c}\text { Superficie } \\
\text { (hectáreas) }\end{array}$ & $\begin{array}{c}\text { Partidas } \\
\text { mixtas }\end{array}$ & $\begin{array}{c}\text { Superficie } \\
\text { (hectáreas) }\end{array}$ \\
\hline Alcasses & 54 & Bovalar & 7 & Casba & 40 \\
Almalafa & 109 & Castell Vell & 59 & Coscollosa & 69 \\
Canet & 90 & Coll de la Garrofera & 12 & Safra & 29 \\
Canyamel & 11 & Collet & 60 & & \\
Censal & 16 & Colomers & 34 & & \\
La Font & 17 & Els Querns & 11 & & \\
La Plana & 18 & Els Pins & 22 & & \\
L'Alcudia & 10 & Estepar & 9 & & \\
Lledó & 34 & Marrada & 6 & & \\
Rafalafena & 55 & Penyeta Roja & 42 & & \\
Ramell & 46 & Ullastrars & 85 & & \\
Taxida & 51 & & & & \\
Vinamargo & 93 & & 347 & Total & 138 \\
Total & 604 & Total & &
\end{tabular}




\section{Los cultivos}

En Castellón de la Plana predominaban los cultivos mediterráneos, como en el resto de huertas fluviales valencianas. Las transformaciones que sufrió la estructura agraria castellonense en las últimas décadas del siglo XV afectaron de manera muy notable a los cultivos, provocando cambios en su distribución superficial. En la Tabla 7 se ha representado la extensión de los cultivos existente en Castellón en 1497.

Tabla 7. Superficie por cultivos

\begin{tabular}{ccccc}
\hline Cultivo & $\begin{array}{c}\text { Supefície } \\
\text { (hectáreas) }\end{array}$ & $\begin{array}{c}\text { Superficie } \\
\text { regadío }\end{array}$ & $\begin{array}{c}\text { Superficie } \\
\text { secano }\end{array}$ & $\begin{array}{c}\text { Superficie } \\
\text { indeterminada }\end{array}$ \\
\hline Tierra de sembradura ${ }^{11}$ & 1.236 & 1136 & 80 & 19 \\
Viña & 232 & 123 & 96 & 14 \\
Majuelo & 30 & 10 & 19 & 1 \\
Olivar & 200 & 95 & 97 & 8 \\
Garroferal & 543 & 45 & 480 & 18 \\
Huertos & 40 & 40 & - & - \\
Marjal & 34 & 34 & - & - \\
Figueral & 6 & 4 & 2 & - \\
Eriazo & 80 & 6 & 72 & 2 \\
Exutal & 11 & 5 & 6 & - \\
Moreral & 5 & 5 & - & - \\
Yermo & 1,5 & - & 1 & - \\
Malear & 4 & - & 4 & - \\
Pinar & 0,8 & 1 & - & - \\
Tierra con arbóreos & 95 & 39 & 52 & 4 \\
Arbóreos combinados & 45 & 17 & 27 & 1 \\
Cultivos con eriazo & 67 & 2 & 57 & 8 \\
Total & 2.630 & 1.562 & 993 & 75 \\
\hline
\end{tabular}

La fuente documental aporta una información mucho más rica para los cultivos arbustivos, que tenían un carácter más estable, que para los cultivos de temporada. Las tierras de sembradura anual se definían de forma genérica como terra. En ellas se cultivaban mayoritariamente cereales, el principal producto agrario en Castellón. Los cereales ocuparían casi la mitad de las tierras cultivadas y más del $70 \%$ de la huerta. El principal cereal en Castellón era el trigo, cultivado principalmente en las tierras irrigadas (Viciano, 2008a, p. 173). En segundo lugar se encontraba la cebada, seguida de otros cereales habituales en los campos valencianos, como la avena, la espelta, el panizo o el mijo, que se podían encontrar tanto en el regadío como en el secano (Domingo, 1983, p. 78). En las tierras de sembradura se cultivaban también legumbres, hortalizas y plantas forrajeras. A finales del siglo XV se produjo una gran difusión de cultivos de carácter comercial, entre los que destacaban el arroz, la caña de azúcar, el lino, el cáñamo y la morera (Viciano, 2003). De todos ellos, del único que poseemos datos cuantitativos es de la morera. Su extensión era todavía limitada en 1497 , rondando las 5 ha, pero su importancia relativa era

\footnotetext{
${ }^{11}$ Se han considerado como tierras de sembradura las que la fuente identifica como terra, terra horta, horta, terra campa, terra de pa y guaret, así como las parcelas de las que no consta el tipo de cultivo.
} 
mayor, dado que la morera se destinaba a la elaboración de seda, un producto altamente rentable en el mercado.

El segundo cultivo en importancia por superficie era el garroferal, con el $20 \%$ del total, siendo el cultivo dominante en el secano. En tercer lugar encontramos la viña y su variedad jóven, el majuelo. Por detrás, el olivo, y otros cultivos arbustivos menores como la higuera. Una parte importante de las parcelas se encontraban sin roturar o incultas, aunque eran propiedad privada y como tal computaban a efectos fiscales. Se trataba de los eriazos, bojares, pinares, maleares y tierras yermas. Destacar también el hecho de que muchas parcelas no se dedicaban a un solo tipo de cultivo, sino que podían conjugar una parte de cultivos de sembradura anual (principalmente cereales) con cultivos arbustivos; combinar diversas especies arbóreas, o incluso disponer de una parte cultivada y otra sin roturar.

Tabla 8. Superficie por cultivos en 1398, 1469, 1497 y 1599

\begin{tabular}{ccccc}
\hline Cultivo & \multicolumn{4}{c}{ Superficie en (hectáreas) } \\
\hline Tierra de sembradura & 1398 & 1468 & 1497 & 1599 \\
Viña & 950 & 1.285 & 1236 & 1559 \\
Majuelo & 125 & 409 & 232 & 667 \\
Olivar & 2 & 64 & 30 & - \\
Ullastrar & - & 115 & 200 & 342 \\
Garroferal & 50 & 28 & - & - \\
Huerto & 52 & 568 & 543 & 961 \\
Marjal & 62 & 25 & 40 & - \\
Bojar & 270 & 17 & 34 & 612 \\
Figueral & 2 & 14 & - & - \\
Donación & 66 & - & 6 & - \\
Alfacara & 1 & - & - & - \\
Eriazo & - & 155 & - & - \\
Exutal & - & 31 & 11 & 568 \\
Moreral & - & 1 & 5 & - \\
Almendral & - & 1 & - & - \\
Estepar & - & 1 & - & - \\
Raudor & - & 3 & - & - \\
Pinar, yermo y malear & - & - & 6 & - \\
Cultivo asociado & - & 63 & - & - \\
Tierra con arbóreos & - & - & 95 & - \\
Arbóreos combinados & - & - & 45 & - \\
Cultivos con eriazo & - & - & 67 & 269 \\
Total & $2.214,22$ & $3.048,16$ & $2.629,73$ & 5.728 \\
\hline & & & & \\
\hline & & & & - \\
\hline
\end{tabular}

Entre los aspectos más destacados de la evolución secular de los cultivos en Castellón, encontramos el acusado descenso del cultivo de la viña a lo largo del siglo XV. El retroceso de la viña es paralelo al incremento de la superficie dedicada a otros cultivos arbustivos, como el olivo o la garrofera, mejor adaptados a la nueva coyuntura socioeconómica que vivía la villa de Castellón. El cultivo de la viña, orientado al autoconsumo y al mercado local, se adaptaba bien al contexto de los años posteriores a la conquista cristiana, ya que daba rendimientos en un período relativamente breve (4 años tras ser plantado), su trabajo 
no requería un instrumental caro ni tampoco de animales de labranza. Sin embargo, exigía una gran inversión en tiempo de trabajo. El descenso demográfico redujo la demanda local de vino y la mano de obra disponible, de modo que la viña dejó de ser un producto rentable (Viciano, 2008a, pp. 171-172).

Por el contrario, cultivos como el olivo o la garrofera daban frutos a muy largo término, pero requerían una menor inversión en mano de obra y un trabajo menos intensivo. La consolidación y arraigamiento de los linajes familiares en la villa favorecía las inversiones a largo plazo, mientras que la nueva coyuntura demográfica estimulaba el cultivo de especies que requirieran una menor dedicación laboral. Al mismo tiempo, se trataba de productos fácilmente almacenables y comercializables en el mercado local y comarcal. De hecho, se produjo en el siglo XV una especialización de cultivos a nivel comarcal dentro de la Plana, articulada por un activo mercado de productos agrarios, dentro de la cual Castellón se especializaría en el cultivo de la garrofera con destino a la alimentación animal (Domingo, 1983, pp. 86-88).

No existía una verdadera diferenciación espacial de los cultivos. La mayor parte de los mismos se cultivaban tanto en el secano como en el regadío. Sí encontramos, sin embargo, una serie de patrones comunes en su distribución. Los huertos y los campos de moreras se solían concentrar en el primer cinturón agrícola alrededor de la ciudad. En las zonas de la huerta más productiva se localizaban también las tierras de sembradura anual. Ciertos cultivos arbustivos, como la olivera o la garrofera, a pesar de distribuirse por todo el término, en ocasiones se encontraban concentrados en partidas concretas del secano como los Ullastrars (el olivo) o el Collet (la garrofera).

\section{E1 parcelario}

La estructura parcelaria medieval de Castellón de la Plana se caracterizaba por su fragmentación y atomización. Han sido localizadas 3.909 parcelas para 1497, de las cuales en 3.552 se detalla la superficie mientras que del resto no consta su extensión. El tamaño medio de los campos de cultivo se situaba en 0,74 ha, una cifra reducida aunque coherente con los parámetros habituales del territorio valenciano. En Castellón la superficie del parcelario se había mantenido relativamente estable, con una ligera tendencia al alza, a lo largo del siglo XV. Si a finales del siglo XIV la superficie media era de 0,62 ha, en 1468 había ascendido a 0,70, cifra superada por las 0,74 ha de 1497 (Sánchez Adell, 1973: 36-45; Domingo, 1977: 41-48).

En el regadío, las parcelas eran sustancialmente más reducidas. La extensión media de los campos de cultivo en la huerta era de 0,69 ha frente a las 0,83 ha del secano. En la huerta se imponía una morfología parcelaria ortogonal, con pequeñas parcelas rectangulares, condicionada por la distribución del sistema hídrico y de la red viaria. También influían en la morfología del parcelario la mayor o menor lejanía de las tierras de cultivo del núcleo de población, la calidad de las tierras y el tipo de cultivo. La pulverización parcelaria era más acusada en las inmediaciones de la villa. Era el lugar donde la presión sobre el espacio cultivado era mayor, donde se concentraban los huertos más productivos y los cultivos de carácter intensivo. En las zonas más alejadas del núcleo urbano, en las tierras de secano menos productivas, las parcelas eran más extensas y a la vez más irregulares. En la Tabla 9 se puede analizar la división del parcelario en 1497 de forma más exhaustiva. 
Tabla 9. Superficie de las parcelas en 1497

\begin{tabular}{ccccc}
\hline $\begin{array}{c}\text { Superficie de la } \\
\text { parcela (hectáreas) }\end{array}$ & $\begin{array}{c}\text { Número de } \\
\text { parcelas }\end{array}$ & $\begin{array}{c}\text { Superficie total } \\
\text { (hectáreas) }\end{array}$ & $\begin{array}{c}\text { Porcentaje } \\
\text { respecto al total } \\
\text { de parcelas }\end{array}$ & $\begin{array}{c}\text { Porcentaje } \\
\text { respecto a la } \\
\text { superficie total }\end{array}$ \\
\hline$<0,5$ & 1.507 & 513 & $42,5 \%$ & $19,5 \%$ \\
0,5 a 1 & 1.429 & 1.062 & $40,2 \%$ & $40,4 \%$ \\
1 a 2 & 498 & 690 & $14 \%$ & $26,3 \%$ \\
2 a 3 & 86 & 206 & $2,4 \%$ & $7,8 \%$ \\
3 a 5 & 19 & 72 & $0,5 \%$ & $2,7 \%$ \\
> 5 & 13 & 87 & $0,4 \%$ & $3,3 \%$ \\
Total & 3.552 & 2.630 & & \\
\hline
\end{tabular}

Junto a la fragmentación del parcelario, el otro gran elemento característico era la dispersión de las parcelas de cultivo en el seno de una misma explotación agraria. Los propietarios poseían una media de 7 parcelas, repartidas entre diferentes partidas del término, tanto de regadío como de secano, estando en ocasiones dichas parcelas muy alejadas entre sí. Un parcelario adaptado perfectamente a los condicionamientos ecológicos y técnicos de una agricultura mediterránea de regadío. Pero también a la estructura social valenciana, caracterizada por el predominio de la familia nuclear y de la pequeña explotación campesina, así como por un sistema de herencia igualitario.

\section{Conclusiones}

La estructura agraria de Castellón compartía, a grandes rasgos, las características básicas que definían la agricultura medieval valenciana. A pesar de que estos rasgos básicos estarán presentes a lo largo del período medieval, el paisaje agrario castellonense evolucionará a lo largo del tiempo. El impacto de la crisis bajomedieval obligó a los agricultores castellonenses a responder a las dificultades readaptando elementos tradicionales e introduciendo novedades. La producción se concentró en las tierras irrigadas de mayor calidad, abandonándose tierras marginales de secano y marjal. Se potenciaron nuevos cultivos relacionados con la actividad comercial, como por ejemplo la morera. Cultivos tradicionales como la viña perdieron importancia frente a otros arbustivos mejor adaptados a la nueva coyuntura demográfica y económica, como la garrofera y el olivo. Las innovaciones afectaron también a las formas de gestión, como muestra la creciente importancia de las explotaciones agrupadas en torno a alquerías. Las dificultades del siglo XV afectarían a todos los productores, pero quienes sobrevivieron a ellas lo hicieron reforzados, con explotaciones más grandes y mejor dotadas. 


\section{Referencias}

Aparici Martí, J (2009): "De molinos, alquerías y poblas. Hábitat mudéjar disperso en la Plana de Vila-real y Burriana (ss. XIV-XVI)", en XI Simposio Internacional de Mudejarismo. Teruel, 18-20 de septiembre de 2008. Actas, Teruel, Centro de Estudios Mudéjares, pp. 707-726.

Del Pozo, J. A. (1995): Prohoms $i$ camperols. Espai agrari i poder local a Vila-real (1362-1386), Vila-real, Delegació de Promoció Cultural.

Díaz de Rábago, C. (1994): La morería de Castelló de la Plana, 1462-1527. Estudio socio-económico de una aljama musulmana medieval, Castellón de la Plana, Ayuntamiento de Castellón de la Plana.

Doménech Vallés, J., Joli Bonias, M. C. (1996-1997): "El impulso de la peita como fuente histórica”, Estudis castellonencs, 7:159-200.

Domingo, C. (1977): "La agricultura de Castellón de la Plana en 1468", Cuadernos de geografía, 21:41-58.

Domingo, C. (1983): La Plana de Castellón. Formación de un paisaje agrario mediterráneo, Castellón de la Plana, Caja de Ahorros y Monte de Piedad de Castellón.

Domingo, C. (1986): “Toponímia i agricultura a la Plana (segles XV-XVIII)", en Col-loqui General de la Societat d'Onomàstica (10è: 1985: València), Valencia, Generalitat Valenciana, pp. 117-123.

Domingo, C. (1998): "Fuentes agrarias precatastrales valencianas. Su utilidad geográfica" Estudios geográficos, 231:225-244.

Domingo, C. (2005): "La construcció de les hortes de La Plana", Boletín de la Sociedad Castellonense de Cultura, 81:45-59.

Furió, A. (1982): Camperols del País Valencià. Sueca, una comunitat rural a la tardor de l'Edat Mitjana, Valencia, Institució Alfons el Magnànim.

Furió, A. (2001): "La domesticación del medio natural: agricultura, ecología y economía en el País Valenciano en la Baja Edad Media", en J. Clement Ramos, Ed., El medio natural en la España medieval. Actas del I Congreso sobre ecohistoria e historia medieval, (celebrado en Cáceres, entre el 29 de noviembre y el 1 de diciembre de 2000), Cáceres, Universidad de Extremadura, pp. 57-103.

Garcia-Oliver, F. (1991): Terra de feudals. El País Valencià en la tardor de l'Edat Mitjana, Valencia, Alfons el Magnànim.

Guinot, E. (1988): "Demografia medieval del nord del País Valencià", en C. Pérez Aparicio, Ed., Estudis sobre la població del País Valencià. Actes de les I jornades d'estudi sobre la població del País V alencià, València-Alacant, 20-22 de març de 1986, Valencia, Edicions Alfons el Magnànim-Institut d'Estudis Juan Gil Albert, Vol. 1, p. 229-249.

Guinot, E. (2002): Las acequias de la Plana de Castelló, Valencia, Conselleria d'Agricultura, Peixca i Alimentació.

Guinot, E. (2005): “Aproximació als molins medievals de Castelló de la Plana” Boletín de la Sociedad Castellonense de Cultura, 81:389-404. 
Guinot, E. (2008): "El paisaje de la Huerta de Valencia. Elementos de interpretación de su morfología espacial de origen medieval", en Historia de la ciudad. Vol. V. Tradición y progreso, Valencia, Icaro-Colegio Territorial de Arquitectos de Valencia-Universidad Politécnica de Valencia, pp. 116-129.

Magdalena Nom de Deu, J. R. (1978): La aljama hebrea de Castellón de la Plana en la Baja Edad Media, Castellón de la Plana, Sociedad Castellonense de Cultura.

Mira, A. J., Viciano, P. (2002): "Arrendaments i parceries. La gestió indirecta de la terra al País Valencià (segles XIV-XV)”, Anuario de estudios medievales, 32:481-500.

Navarro Espinach, G. (1998): "Joan Santalínia i altres paraires de Castelló a la fi del segle XV", Actes del V Congrés d'Història i Filologia de la Plana, Nules, Ajuntament de Nules, pp. $155-178$.

Peris Albentosa, T. (1985): "Anàlisi crítica i guia metodològica dels cappatrons de la peita de l'Arxiu Municipal d'Alzira”, Al-Gezira. Revista d'estudis, 1:113-147.

Rabassa, C. (1999) “L'extensió del regadiu de Castelló durant la Baixa Edat Mitjana", Boletín de la Sociedad Castellonense de Cultura, 75:617-650.

Sánchez Adell, J. (1973): "Estructura agraria de Castellón de la Plana en 1398”, Cuadernos de geografía, 12:31-59.

Sánchez Adell, J. (1982): Castellón de la Plana en la Baja Edad Media, Castellón de la Plana, Sociedad Castellonense de Cultura.

Sánchez Adell, J. (1994): “Toponimia rural de Castellón de la Plana en la Edad Media, s. XIV-XV", Boletin de la Sociedad Castellonense de Cultura, 70:517-600.

Torró, J. (2010): “Tierras ganadas. Aterrazamiento de pendientes y desecación de marjales en la colonización cristiana del territorio valenciano", en H. Kirchner, Ed., Por una arqueología agraria. Perspectivas de investigación sobre espacios de cultivo en las sociedades medievales hispánicas, Oxford, British Archaeological Reports, pp. 157-172.

Traver Tomás, V. (1982): Antigüedades de Castellón de la Plana. Estudios histórico-monográficos de la villa y su vecindario. Riqueza y monumentos, Castellón de la Plana, Ayuntamiento de Castellón de la Plana.

Viciano, P. (2003): "Pagesos que innoven. La petita explotació en les transformacions agràries de la fi de l'Edat Mitjana", en M. Barceló, Ed., El feudalisme comptat $i$ debatut. Formació $i$ expansió del feudalisme català, Valencia, Universitat de València, pp. 503-522.

Viciano, P. (2007): “La projecció d'una vila en l'espai rural”, en Senyors, camperols i mercaders. El món rural valencià al segle XV, Catarroja, Afers, pp. 81-117.

Viciano, P. (2008a): Regir la cosa pública. Prohoms i poder local a la vila de Castelló (segles XIV$X V)$, Valencia, Universitat de València.

Viciano, P. (2008b): "Producción agraria e impuesto municipal directo. La tasación de la riqueza en los padrones de riqueza valencianos (siglos XIV-XV)", en R. Vallejo, Ed., Los tributos de la tierra. Fiscalidad y agricultura en España (siglos XII-XX), Valencia, Universitat de València, pp. 245-262.

Viciano, P. (2011): "Bracers i cavadors: los jornaleros en el mundo rural valenciano a fines de la Edad Media", en XIII Congreso de Historia Agraria. Congreso Internacional de la SEHA (Lleida, 12 - 14 de mayo de 2011) (en prensa). 
Viciano, P. (2012): Els peus que calciguen la terra. Els llauradors del País Valencià a la fi de l'edat mitjana, Valencia, Universitat de València. 